\title{
Computed tomographic estimation of lung dimensions throughout the growth period
}

\author{
P.A. de Jong*,\#,ף, , F.R. Long" ${ }^{\#}$, J.C. Wong ${ }^{\Uparrow}$, P.J. Merkus*, H.A. Tiddens*, \\ J.C. Hogg and H.O. Coxson ${ }^{\top,+}$
}

ABSTRACT: The aim of the current study was to use computed tomography (CT) to estimate airway wall and lumen, and arterial and parenchyma dimensions in children throughout the growth period, and to provide normative data to study alterations caused by pulmonary disease.

Clinical CT scans reported as normal that were performed in children for nonpulmonary and noncardiac reasons were analysed for lung weight, gas volume, lung expansion, lung surface/ volume ratio, airway wall area, airway lumen area, airway lumen perimeter, arterial area and airway surface length/area ratio.

The age range of the 50 subjects was $0-17.2$ yrs. The data showed only little increase in lung expansion throughout childhood $(n=32)$. There was substantial variability in lung expansion between subjects. Airway wall and lumen and arterial area were exponentially associated with subjects' height $(n=50)$. Airway surface length/area ratio was linearly associated to alveolar surface/volume ratio.

The data from the current study provide normative computed tomography estimates of airway wall and lumen, and arterial and parenchyma dimensions throughout the growth period that may be useful for the study of alterations in disease.

KEYWORDS: Airway, alveolus formation, childhood, computed tomography, lung development, pulmonary artery

B etween one-third and one-half of the adult number of alveoli are present in the human lung at birth [1]. This number increases rapidly by a process of septation of the primary saccules and probably reaches adult values between 1.5-2 yrs of age, and certainly by 8 yrs of age [1-5]. After the phase of rapid alveolar addition is completed, the number of alveoli remains constant and the lung continues to grow by increasing the dimensions of all of the lung structures $[1,4,5]$. In contrast to alveoli, the number of conducting airways and pulmonary arteries is complete at birth and they only increase in size during postnatal growth $[6,7]$. Whether airway sizes and airway growth patterns differ between sexes in infancy [8-17] or later in childhood [18-25] remains controversial.

Alterations in the growth of lung structures occur secondary to a wide variety of congenital [26] and developmental insults [27-29], yet little normative data exists regarding how lung structure changes with age or height. Therefore, a better understanding of lung growth in health and disease is needed. Computed tomography (CT) scanning has made it possible to study lung structure in vivo [21,30-34] and provides a useful tool for evaluation of both lung disease [28, 35, 36] and normal lung parenchyma (lung weight, gas volume and expansion) [37].

Previously, the current authors estimated lung parenchyma dimensions in a cohort of children ranging from birth through to adolescence [37]. In the present study, airway wall and lumen dimensions of the conducting airways and dimensions of the accompanying pulmonary artery in addition to the lung parenchyma were estimated in a different cohort of children. The aim of the present study was to use CT to estimate airway wall and lumen, and arterial and parenchyma dimensions in children throughout the growth period, and to provide normative data to study alterations caused by pulmonary disease.

\section{METHODS}

\section{Subjects}

In the current study, 50 subjects from Columbus Children's Hospital (OH, USA) were included who were undergoing $\mathrm{CT}$ investigation for nonpulmonary malignancies. Only CT scans initially reported as normal, with confirmation of this opinion by a second radiologist, were
AFFILIATIONS

*Erasmus MC-Sophia, Dept of Paediatric Pulmonology and Allergology, Rotterdam, The Netherlands.

\#Columbus Children's Hospital, the Children's Radiological Institute, Columbus, OH, USA.

- James Hogg iCAPTURE Centre for Cardiovascular and Pulmonary Research, St Paul's Hospital, and ${ }^{+}$Dept of Radiology, Vancouver General Hospital, University of British Columbia Vancouver, BC, Canada.

CORRESPONDENCE

H.O. Coxson

Dept of Radiology Vancouver General Hospital 855 West 12th Avenue Room 3350 JPN Vancouver BC Canada V5Z 1M9 Fax: 16048754319

E-mail: harvey.coxson@vch.ca

Received:

June 162005

Accepted after revision: November 012005 
included in the study (table 1). The study was approved by the ethical review board of Columbus Children's Hospital.

\section{Computed tomography scans}

All CT scans were acquired using a GE lightspeed Ultra 8-slice CT scanner (General Electric Healthcare, Milwaukee, WI, USA) using a peak potential of 120 kilovolts peak and a beam current ranging from 30-120 milli-Amperes per second and were reconstructed using both a low resolution (GE "Standard") and a high resolution (GE "Bone") algorithm. Contiguous 1.25$\mathrm{mm}$ thick images were acquired in 32 of the subjects, either after a breath-hold instruction in the children $>5$ yrs of age $(n=17)$, or using a previously described method of volume control in children $<5$ yrs of age [38-40] $(n=15)$. Briefly, the infants were sedated and an apnoea was briefly induced to allow lungs to be inflated to an airway pressure of $25 \mathrm{cmH}_{2} \mathrm{O}$ using a face-mask during the CT scanning [28]. The remaining 18 subjects only received a limited $1.25-\mathrm{mm}$ thick CT scan at four levels following a previously published protocol. No contrast media was used in any of the CT scanning procedures.

\section{Computed tomography parenchyma analysis}

The CT scans were transferred to the James Hogg iCAPTURE (Imaging, Cell Analysis, and Phenotyping Toward Understanding Responsive, Reparative, Remodelling, and Recombinant Events) Centre for Cardiovascular and Pulmonary Research (Vancouver, BC, Canada) for analysis. The 18 CT scans with limited images were only used to estimate airway wall and lumen and arterial dimensions, and not to estimate lung parenchyma. The remaining $32 \mathrm{CT}$ scans were also used for parenchymal, airway and artery analysis, as described below.

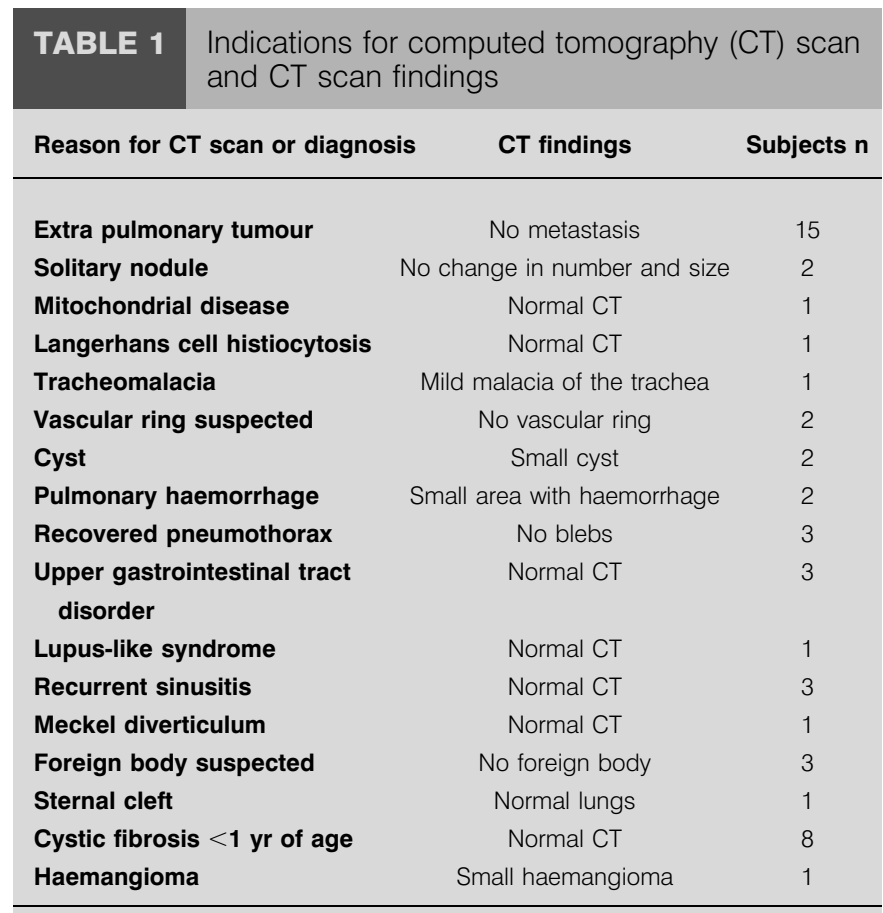

Of the $50 \mathrm{CT}$ scans, 19 have been previously reported [28]. In that report, airway wall and lumen and arterial dimensions were measured using a different measurement programme and, in that study, the normal dimensions were compared with cystic fibrosis patients.
The lung parenchyma was analysed using the "standard" reconstruction algorithm, as previously described [33, 34]. Briefly, the lung was segmented from the chest wall and surrounding structures, and the lung volume was calculated by summing the voxels within the lung and density was calculated from the $X$-ray attenuation values. Lung weight was calculated by multiplying the lung density by volume. Lung expansion, in millilitres of gas per gram of tissue, was calculated by subtracting the inverse of the density of tissue (assumed to be $1.065 \mathrm{~g} \cdot \mathrm{mL}^{-1}$ [41]) from the inverse of the CTmeasured lung density $[33,34]$. Lung alveolar surface area to total lung volume ratio $(\mathrm{S} / \mathrm{V})$ was calculated using the lung expansion values at total lung capacity (TLC) as previously described [34]:

$$
\mathrm{S} / \mathrm{V} \text { lung }=\mathrm{e}^{6.84-(0.32 \times \text { lung expansion at TLC })}
$$

CT-calculated lung weight was compared with previously reported post mortem values from children with normal lungs [42]. The CT-determined gas volume was compared with predicted normal values for functional residual capacity and TLC using standard prediction equations based on body length $[1,4,43-45]$. CT-calculated lung expansion was compared between males and females. To overcome the problem of different inflation levels between subjects during the CT procedure, lung expansion at full lung inflation was calculated by dividing the predicted TLC by the CTcalculated lung weight (hereafter referred to as lung expansion at TLC).

\section{Computed tomography airway and artery analysis}

Airway wall and lumen and arterial dimensions were measured in the 50 subjects at specified locations of the bronchial tree (fig. 1), as previously described [31, 32]. The measurement locations were: trachea $(\mathrm{T})$, right bronchus intermedius (RBI), right apical bronchus (RAB), and the first, second and third branches after the RAB (RAB1, RAB2 and RAB3 respectively). Airway lumen area (LA) and perimeter (Pi) were measured from $\mathrm{T}$ through to RAB2, since RAB3 was too small to be reliably measured. Arterial area (AA) was measured from RAB through to RAB3, since T and RBI do not have a measurable pulmonary artery. In the 18 subjects with only four CT images, a given airway branch was excluded if it could not be found. The measurements were performed by manually placing a seed in the lumen of the airway or artery and casting 64 rays from this point into the parenchyma. The borders of inner and outer airway wall or outer arterial wall were determined using the full-width at half maximum principle [46]. Rays that were too long or too short were manually edited, and the dimensions calculated by connecting the ends of the rays using a spline function. LA is defined as the area internal to the inner wall in airways and the Pi is the length of the inner boundary of the rays. AA is the area internal to the outer wall of the artery.

Trachea lumen area was compared with previously published values of CT-estimated trachea lumen area [47, 48]. Airway lumen Pi (length) was divided by LA to estimate airway surface length/area ratio ( $\mathrm{Pi} / \mathrm{LA})$. The airway surface length/ area ratio was compared with the lung alveolar surface area/ volume ratio. 


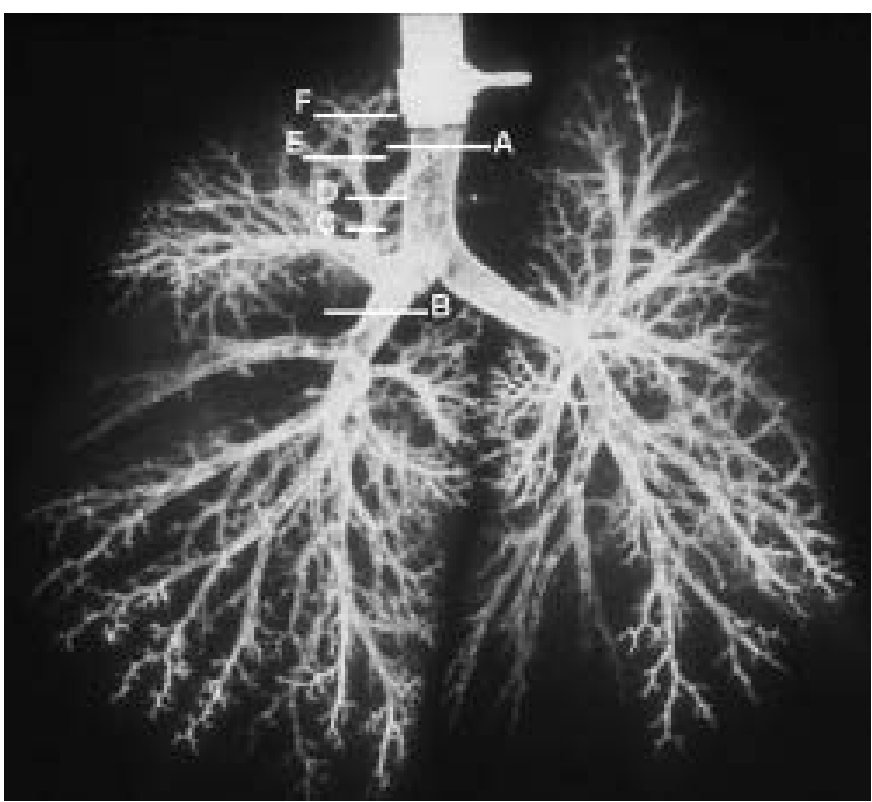

FIGURE 1. Sites of airway-artery measurements shown on a bronchial tree. This bronchogram clearly demonstrates the divisions of the airway tree where the measurements were performed on computed tomography for the present study. A: trachea, lumen area and wall area; B: right bronchus intermedius, lumen and wall area; C: right apical bronchus (RAB), lumen and wall area and arterial area; $D$ : first branch after $\mathrm{RAB}$, lumen and wall area and arterial area; $\mathrm{E}$ : second branch after $\mathrm{RAB}$, lumen and wall area and arterial area; $F$ : third branch after RAB, arterial area.

\section{Statistical analysis}

The significance level was set as $\mathrm{p}<0.05$. For all variables, mean \pm SD (range) values were calculated. Exponential, power, linear and logistic curve fitting with 95\% confidence intervals (CI) was performed to correlate airway wall, LA, AA, lung weight and lung expansion at TLC with subject height. The line of best fit was reported. Spearman correlation was used to determine the relationships between LA of the trachea and the other measured airways, between the AA of the right apical bronchus and the other measured arteries and between the alveolar $\mathrm{S} / \mathrm{V}$ ratio and the airway $\mathrm{Pi} / \mathrm{LA}$ ratio.

\section{RESULTS \\ Study population}

The demographics and the total lung CT measurements for the study subjects are shown in table 2 .

\section{Parenchyma}

Figure 2 shows that there is a significant power law relationship between CT measured lung weight and the height of the subject $\left(C T\right.$ weight $=35.1 \times \exp ^{\text {height } \times 0.0183} ; \mathrm{R}^{2}=0.96, \mathrm{p}<0.001$; fig. 2). Furthermore, there is a significant power law relationship between both CT-measured gas volume and lung expansion at TLC and the height of the subject (gas volume $=0.0283 \times$ height $^{2.247} ; \mathrm{R}^{2}=0.85, \mathrm{p}<0.001 ; \mathrm{CT}$ expansion at $\mathrm{TLC}=0.172 \times$ height $^{0.735}, \mathrm{R}^{2}=0.66 ; \mathrm{p}<0.001$; fig. 3 ).

\section{Airways and arteries}

There is a significant exponential relationship between $\mathrm{LA}_{\text {trachea }}$ of the study subjects height $\left(\mathrm{R}^{2}=0.90, \mathrm{p}<0.001\right)$, which compares favourably to published normal values [47, 48]. Furthermore, there is a strong correlation between the trachea $\left(\mathrm{LA}_{\text {trachea }}\right)$ and all the other measured airways $\left(\mathrm{R}^{2}\right.$ : $\mathrm{LA}_{\mathrm{RBI}}=0.93, \mathrm{LA}_{\mathrm{RAB}}=0.82, \mathrm{LA}_{\mathrm{RAB} 1}=0.87$ and $\mathrm{LA}_{\mathrm{RAB} 2}=0.91$; all $\mathrm{p}<0.0001)$. There is also a strong correlation between the arterial dimension of the $\mathrm{RAB}\left(\mathrm{AA}_{\mathrm{RAB}}\right)$ and all the other measured arteries $\left(\mathrm{R}^{2}: \mathrm{AA}_{\mathrm{RAB} 1}=0.85, \quad \mathrm{AA}_{\mathrm{RAB} 2}=0.87\right.$; and $\mathrm{AA}_{\mathrm{RAB} 3}=0.87$ all $\left.\mathrm{p}<0.0001\right)$. The relationship between LA and subject height for the various airway generations is shown

TABLE 2 Demographics and the total lung computed tomography (CT) measurements for the study subjects

\begin{tabular}{|c|c|c|c|c|c|c|c|}
\hline Age yrs & $\begin{array}{l}\text { Subjects } \\
\mathrm{n} \text { (male) }\end{array}$ & $\begin{array}{l}\text { Subjects with } \\
\text { four images }{ }^{\#}\end{array}$ & Subject height $\mathrm{cm}$ & CT weight $g$ & CT gas volume $\mathrm{mL}$ & Predicted TLC mL & $\begin{array}{l}\text { Predicted TLC/CT } \\
\text { weight } \mathrm{mL} \cdot \mathrm{g}^{-1}\end{array}$ \\
\hline 1 & $11(8)$ & 5 & $79 \pm 4$ & $151 \pm 25$ & $546 \pm 177$ & $723 \pm 109$ & $5.0 \pm 0.9$ \\
\hline 2 & $5(2)$ & 3 & $88 \pm 4$ & $217 \pm 51$ & $910 \pm 88$ & $992 \pm 120$ & $4.7 \pm 2.2$ \\
\hline 3 & $3(3)$ & 2 & $101 \pm 2$ & 214 & 847 & $1351 \pm 41$ & 6.1 \\
\hline 7 & $2(1)$ & 0 & $121 \pm 6$ & $335 \pm 141$ & $1125 \pm 848$ & $2170 \pm 377$ & $6.9 \pm 1.8$ \\
\hline 9 & $1(1)$ & 0 & 131 & 365 & 1726 & 2749 & 7.5 \\
\hline 10 & $1(0)$ & 0 & 144 & 449 & 1818 & 3320 & 7.4 \\
\hline 11 & $1(0)$ & 0 & 139 & 564 & 3293 & 3031 & 5.4 \\
\hline 12 & $2(1)$ & 0 & $151 \pm 1$ & $566 \pm 58$ & $2617 \pm 933$ & $3855 \pm 55$ & $6.8 \pm 0.6$ \\
\hline 13 & $1(0)$ & 0 & 158 & 598 & 1034 & 4216 & 7.1 \\
\hline 17 & $3(1)$ & 0 & $167 \pm 7$ & $711 \pm 199$ & $2731 \pm 1052$ & $4950 \pm 724$ & $7.2 \pm 1.3$ \\
\hline
\end{tabular}

Data are presented as mean \pm SD or $n$ unless otherwise stated. TLC: total lung capacity; NA: not assessed. \#: For subjects with only four CT images per CT scan, lung parenchyma dimensions could not be estimated. No subjects aged 6 and 8 yrs were available. 


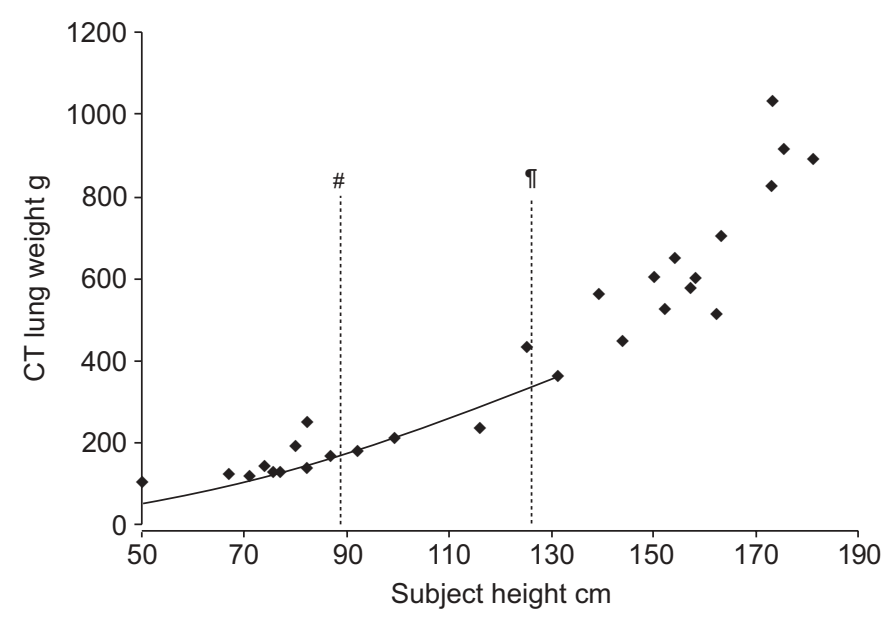

FIGURE 2. Computed tomography (CT)-measured lung weight and predicted lung weight versus subjects' height. Subjects' height at $\sim 2$ yrs ( $\left(^{*}\right)$ and 8 yrs (") of age is indicated by the vertical dotted lines. $\bullet$ : CT-measured lung weight. — predicted lung weight from published data on autopsy specimens [42]. The equation for the regression is: CT measured lung weight $=35.1 \times \exp ^{\text {subject }}$ height $\times 0.0183\left(R^{2}=0.96, p<0.0001\right)$

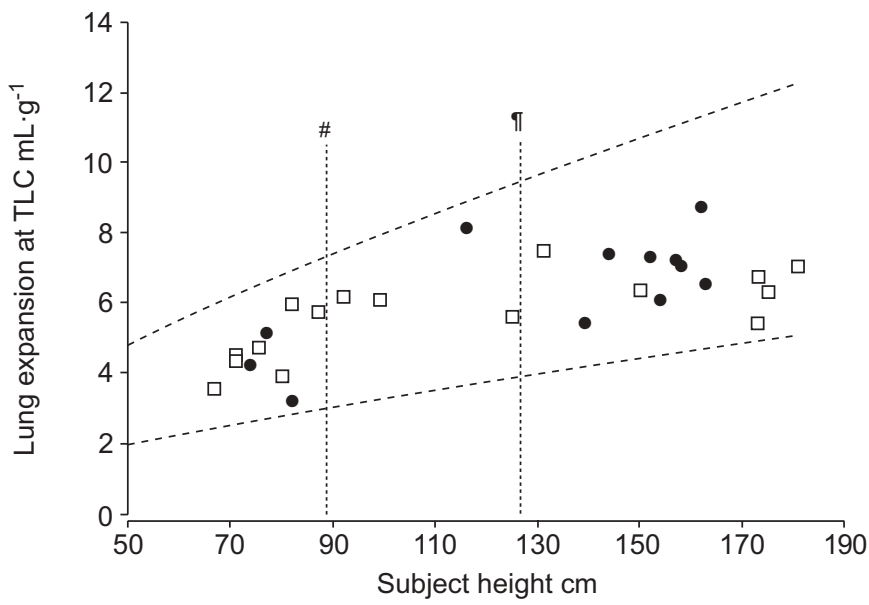

FIGURE 3. Computed tomography measured lung expansion at total lung capacity (TLC) versus subjects' height. The data from males and females were grouped for calculation of the regression equation due to small sample size. Subjects' height at $\sim 2$ yrs $\left(^{\#}\right)$ and 8 yrs (") of age is indicated by the vertical dotted lines. - females; $\square$ : males. -----: 95\% confidence intervals calculated for males and females together. The equation of the regression is: expansion at TLC $=0.172 \times$ height $^{0.735}\left(R^{2}=0.66, p<0.001\right)$.

in figure 4 (95\% CI are not shown). The graphs for airway wall area and arterial area were similar and are not shown, but the equations for airway wall and lumen and artery area versus subjects' height are listed in table 3.

\section{Airway versus parenchyma}

The relationship between surface/volume ratio of the lung and surface/volume ratio of the various airways is shown in figure 5. The correlation between alveolar surface/volume ratio and the airway perimeter/area ratio of the $T, R B I, R A B$, RAB1 and RAB2 was $0.62,0.51,0.59,0.42$ and 0.44 , respectively (all $\mathrm{p}<0.0001)$.

\section{DISCUSSION}

This study uses CT scans to estimate airway wall and lumen, arterial and parenchyma dimensions (lung weight, gas volume, lung expansion, surface/volume ratio) in children throughout the growth period. These data show that when lung expansion is corrected for predicted TLC, there is only a small gradual change in lung expansion at TLC. This suggests that, even during the first 2 yrs of life, when the septation process results in rapid alveolar addition, lung weight does not increase as rapidly as the gas volume. Using pathological specimens, THURLBECK [3] found an increase in lung expansion from $3 \mathrm{~mL}$ of gas per gram of tissue $\left(\mathrm{mL} \cdot \mathrm{g}^{-1}\right)$ at birth to $\sim 8 \mathrm{~mL} \cdot \mathrm{g}^{-1}$ at 6 yrs of age. These values correspond well to the current authors' values of $\sim 3 \mathrm{~mL} \cdot \mathrm{g}^{-1}$ at birth and $7.5 \mathrm{~mL} \cdot \mathrm{g}^{-1}$ in adolescence obtained using CT. However, these findings are markedly different from the current authors' previous report [37], where they found a decrease in lung expansion during the
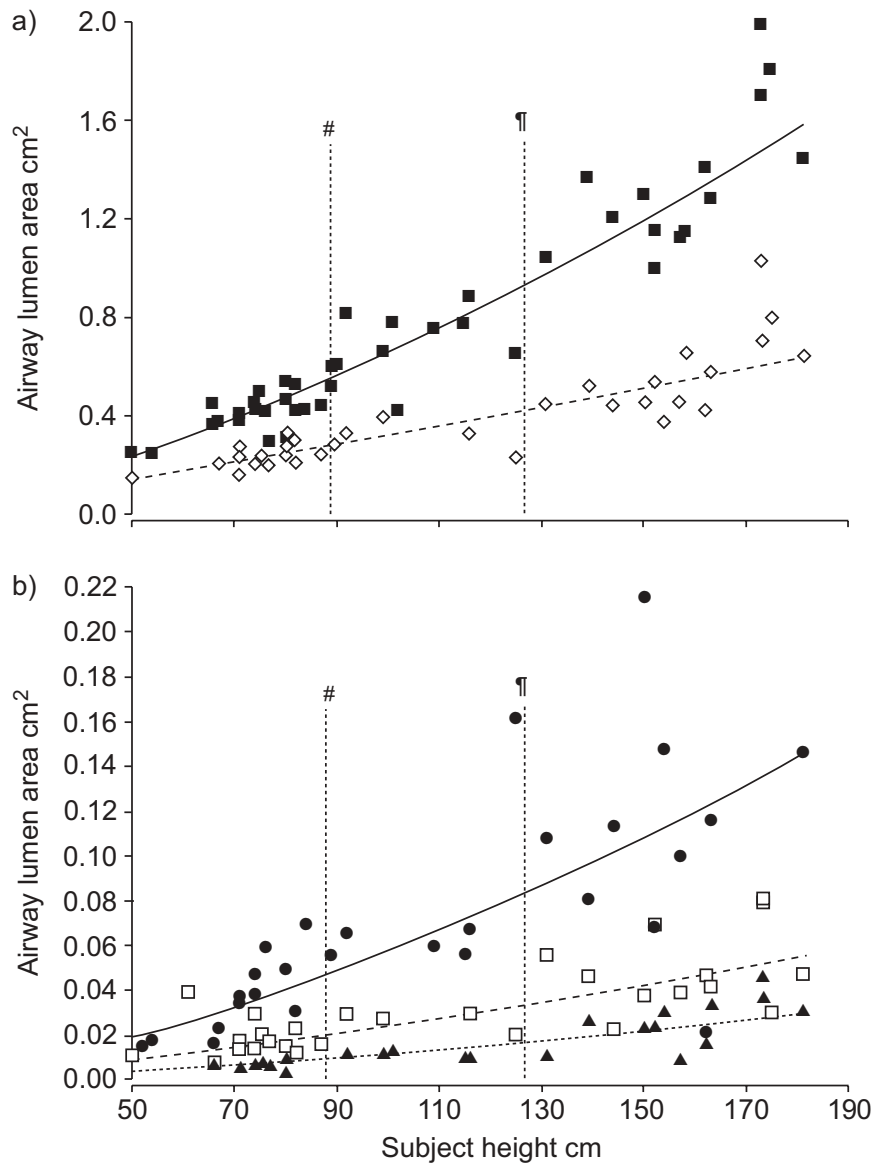

FIGURE 4. a) Measurements of lumen area for trachea $(\diamond)$ and right bronchus intermedius (RBI; - $)$ are plotted against the subject height. The power-law regression lines are shown for the trachea $(-)$ and the RBI (----). The 95\% confidence intervals are not shown. b) Measurements of lumen area for right apical bronchus (RAB; $\bullet$ ), first branch after RAB $(\square)$ and second branch after $\operatorname{RAB}(\mathbf{\Lambda})$ are plotted against the subject height. The linear regression lines are shown for RAB (-), RAB1 (----) and RAB2 (….....). The 95\% confidence intervals are not shown. The linear regression lines and corresponding equations are provided for each generation in table 3 . The data were grouped for males and females due to small sample size. Subjects' height at $\sim 2$ yrs (") and 8 yrs (") of age is indicated by the vertical dotted lines. 
TABLE 3 Power law regression equations for computed tomography estimated airway and arterial areas versus subject height

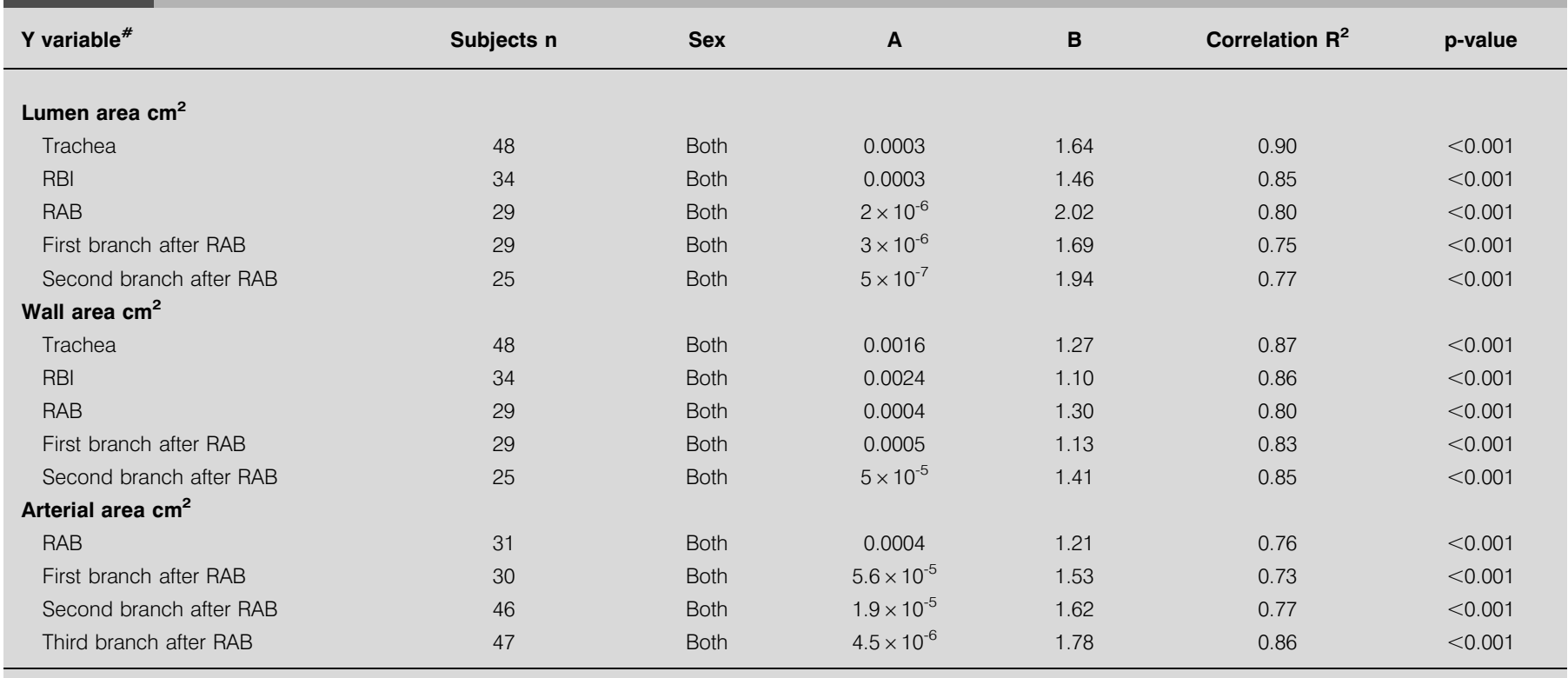

Y: the airway or artery variable (lumen, wall or artery area); A: the $Y$ intercept; B: the slope (power law exponent) of the regression; RBI: right bronchus intermedius; RAB right apical bronchus. ${ }^{\#}: \mathrm{Y}=\mathrm{A} \times$ subject height in $\mathrm{cm}$.

first 2 yrs of life. The current authors think that this difference can be explained by the difference in lung inflation techniques used between these two studies. In the original study, the CT scans were acquired either after a breath-hold instruction in older subjects, or during quiet breathing in younger subjects. In the current study, images were acquired from younger subjects using a lung-inflation technique that allowed the lungs to be inflated to an airway pressure of $25 \mathrm{cmH}_{2} \mathrm{O}$ [40]. This underlines the need for better quality control in the acquisition of CT scans to allow for the investigation of small alterations in lung structure. In the present study, because of the difference in lung inflation, each subject was corrected to a percentage of their predicted maximal lung expansion by dividing the measured or predicted TLC by CT-measured lung weight (fig. 3). Using this approach, the data shows that there is substantial variability in lung expansion at TLC during the growth period. This variation could be caused by the fact that predicted values were used for TLC, and it may show variability in lung expansion that exists between individuals. The CT measurement of lung weight, however, has been shown to correlate very well with gravimetric measurements of lung weight [37] and, in this study, shows a strong association with subject height (fig. 2). This suggests that a CT measurement of lung weight may be the most useful parameter by which to evaluate parenchymal changes throughout the growth period.

The tracheal lumen area compared favourably with previous CT estimates from GRISCOM and coworkers $[47,48]$ and with post mortem studies, bronchographic studies and other CT studies (data not shown) [49]. In the present study, the authors were also able to measure airways smaller than the trachea down to the limit that current CT scanners allow (approximately lumen diameter of $1 \mathrm{~mm}$ ). No difference in airway sizes could be demonstrated between males and females, in contrast with functional studies in children and adults, which indicated that males have smaller airways in infancy and larger airways after puberty than females $[8,9,11,19,20,23,44]$. This suggests that the changes in function might be due to differences in smaller airways, which cannot be measured by $\mathrm{CT}$, or to type II errors in the current study due to the small sample size. In addition, based on the current data, it is not possible to determine if the conducting airways are relatively larger or smaller in infancy. Potentially, CT studies (preferably longitudinal) can solve these controversial issues.

Less variation was found in the airway wall and lumen and arterial lumen measurements than was found in the lung expansion measurements. The variation present in the airway measurements could be a result of measurement error due to volume-averaging effects of the $\mathrm{CT}$ scan or failure of the measurement algorithm, $[32,50]$, the effect of lung inflation on smooth muscle tone [51], or the real variability between subjects. The current authors speculate that the variability due to inter-subject differences could have implications for the subsequent development of airway disease or respiratory symptoms in subjects with relatively narrow airways [24, 30], however, this requires further study.

The surface/volume ratio of alveoli was linearly related to the perimeter/lumen area ratio of the airways, suggesting that the growth of the airway and the alveolus is closely linked. However, as this is a cross-sectional study it is unknown if this linear relationship exists at all stages of development. A longitudinal CT study would be required to establish this relationship, and could address the hypothesis that conducting airway growth is isotropic or dysanaptic [19] with parenchymal development. Unfortunately, the radiation exposure due to current CT protocols currently limits this approach to subjects receiving CT scans of the thorax for other reasons. 

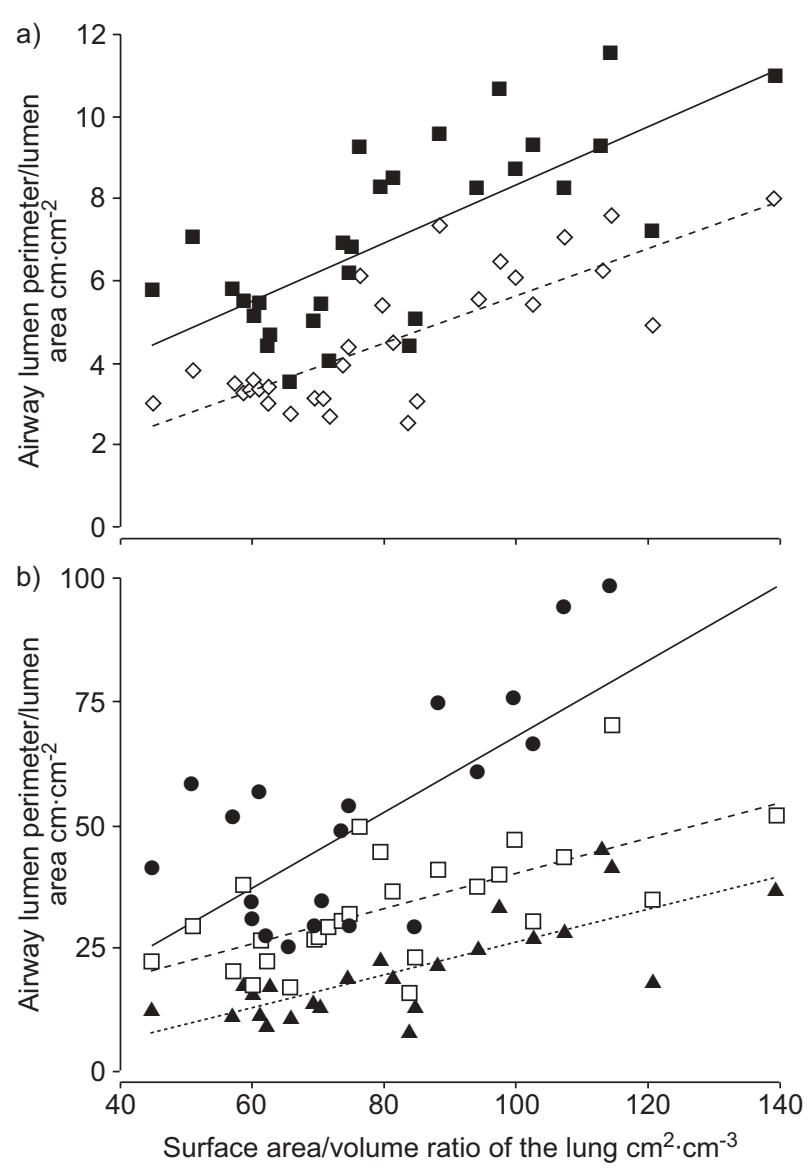

FIGURE 5. Alveolar surface area/lung volume ratio versus airway lumen perimeter/airway lumen area ratio. a) Measurements of lumen perimeter/area ratio for trachea $(\mathbf{\square})$ and right bronchus intermedius $(\mathrm{RBI} ; \diamond)$ are plotted against the lung surface area/volume ratio. The regression line is shown for the trachea $(-)$ and the RBI (-----). The 95\% confidence intervals are not shown. b): Measurements of lumen perimeter/area ratio for right apical bronchus (RAB; $\bullet$ ), RAB1 ( $\square$ ) and RAB2 $(\mathbf{\Lambda})$ are plotted against the lung surface area/volume ratio. The linear regression line is shown for the RAB (-), RAB1 (-----) and RAB2 (…....). The 95\% confidence intervals are not shown. These data show that the linear dimensions of the lung parenchyma $\left(\mathrm{cm}^{-1}\right)$ are linearly related to the linear dimensions of the airway $\left(\mathrm{cm}^{-1}\right)$.

There are a number of limitations to this study. The first, major limitation is that, because of concerns over radiation exposure, this study only provides cross-sectional information about lung growth. Secondly, there is neither pathological validation of the measurements in these subjects, nor access to pulmonary function. Thirdly, the small number of subjects studied made it difficult to analyse differences between males and females. Finally, as only airways in the right upper lobe were measured, it must be assumed that the growth patterns are the same in other lobes.

In conclusion, these data show that, when lung volume is corrected to total lung capacity, lung weight increases in such a way that overall lung expansion is more stable than previously reported between birth and 17 yrs of age. Also, in the period of rapid alveolar addition, there is only a slight increase in lung expansion at total lung capacity, suggesting that the increase in gas volume associated with alveolar addition requires a very limited increase in lung tissue. The sole measurement of lung weight may be enough to estimate changes in lung parenchyma throughout the growth period. No evidence was found that computed tomography measured airways are larger in infants or in male subjects, which may be related to sample size. Nevertheless, the current data provide useful normative estimates of airway, artery and maybe parenchymal growth, which may be applicable to children with pulmonary diseases, particularly cystic fibrosis and asthma, where changes in airway dimensions are hallmarks of the disease.

\section{ACKNOWLEDGEMENTS}

The authors would like to thank A.-T. Tran and K.P. Whittall for their invaluable expertise with the CT analysis algorithms, and Y. Nakano for his support with the airway and arterial measurements.

\section{REFERENCES}

1 Thurlbeck WM. Postnatal human lung growth. Thorax 1982; 37: 564-571.

2 Dunnill M. Postnatal growth of the lung. Thorax 1962; 17: 329-333.

3 Thurlbeck WM. Postnatal growth and development of the lung. Am Rev Respir Dis 1975; 111: 803-844.

4 Zeltner TB, Burri PH. The postnatal development and growth of the human lung. II. Morphology. Respir Physiol 1987; 67: 269-282.

5 Hislop A, Wigglesworth J, Desai R. Alveolar development in the human fetus and infant. Early Hum Dev 1986; 13: $1-11$.

6 Reid L. 1976 Edward B.D. Neuhauser lecture: the lung growth and remodeling in health and disease. AJR Am J Roentgenol 1977; 129: 777-788.

7 Hislop AA. Airway and blood vessel interaction during lung development. J Anat 2002; 201: 325-334.

8 Jones M, Castile R, Davis S, et al. Forced expiratory flows and volumes in infants. Normative data and lung growth. Am J Respir Crit Care Med 2000; 161: 353-359.

9 Lambert RK, Castile RG, Tepper RS. Model of forced expiratory flows and airway geometry in infants. J Appl Physiol 2004; 96: 688-692.

10 Stocks J. The functional growth and development of the lung during the first year of life. Early Hum Dev 1977; 1: 285-309.

11 Tepper RS, Morgan WJ, Cota K, Wright A, Taussig LM. Physiologic growth and development of the lung during the first year of life. Am Rev Respir Dis 1986; 134: 513-519.

12 Hislop A, Muir DC, Jacobsen M, Simon G, Reid L. Postnatal growth and function of the pre-acinar airways. Thorax 1972; 27: 265-274.

13 Horsfield K, Gordon WI, Kemp W, Phillips S. Growth of the bronchial tree in man. Thorax 1987; 42: 383-388.

14 Cudmore R, Emery J, Mithal A. Postnatal growth of the bronchi and bronchioles. Arch Dis Child 1962; 37: 481-484.

15 Davies G, Reid L. Growth of the alveoli and pulmonary arteries in childhood. Thorax 1970; 25: 669-681.

16 Hogg JC, Williams J, Richardson JB, Macklem PT, Thurlbeck WM. Age as a factor in the distribution of lower-airway conductance and in the pathologic anatomy 
of obstructive lung disease. N Engl J Med 1970; 282: 1283-1287.

17 Mansell AL, Bryan AC, Levison H. Relationship of lung recoil to lung volume and maximum expiratory flow in normal children. J Appl Physiol 1977; 42: 817-823.

18 Hibbert M, Lannigan A, Raven J, Landau L, Phelan P. Gender differences in lung growth. Pediatr Pulmonol 1995; 19: 129-134.

19 Green M, Mead J, Turner JM. Variability of maximum expiratory flow-volume curves. J Appl Physiol 1974; 37: 67-74.

20 Martin TR, Castile RG, Fredberg JJ, Wohl ME, Mead J. Airway size is related to sex but not lung size in normal adults. J Appl Physiol 1987; 63: 2042-2047.

21 Pagtakhan RD, Bjelland JC, Landau LI, et al. Sex differences in growth patterns of the airways and lung parenchyma in children. J Appl Physiol 1984; 56: 1204-1210.

22 Martin TR, Feldman HA, Fredberg JJ, Castile RG, Mead J, Wohl ME. Relationship between maximal expiratory flows and lung volumes in growing humans. J Appl Physiol 1988; 65: 822-828.

23 Briscoe $W$, Dubois A. The relationship between airway resistance, airway conductance and lung volume in subjects of different age and body size. J Clin Invest 1958; 37: 1279-1285.

24 Merkus PJ, Borsboom GJ, Van Pelt W, et al. Growth of airways and air spaces in teenagers is related to sex but not to symptoms. J Appl Physiol 1993; 75: 2045-2053.

25 Merkus PJ, ten Have-Opbroek AA, Quanjer PH. Human lung growth: a review. Pediatr Pulmonol 1996; 21: 383-397.

26 Ijsselstijn H, Tiboel D, Hop WJ, Molenaar JC, de Jongste JC. Long-term pulmonary sequelae in children with congenital diaphragmatic hernia. Am J Respir Crit Care Med 1997; 155: 174-180.

27 Tiddens H, Silverman M, Bush A. The role of inflammation in airway disease: remodeling. Am J Respir Crit Care Med 2000; 162: Suppl. 2, S7-S10.

28 Long FR, Williams RS, Castile RG. Structural airway abnormalities in infants and young children with cystic fibrosis. J Pediatr 2004; 144: 154-161.

29 de Jong PA, Nakano Y, Lequin MH, et al. Progressive damage on high resolution computed tomography despite stable lung function in cystic fibrosis. Eur Respir J 2004; 23: 93-97.

30 Hislop AA. Lung growth and computed tomography. Eur Respir J 2003; 22: 195-196.

31 Nakano Y, Muro S, Sakai H, et al. Computed tomographic measurements of airway dimensions and emphysema in smokers. Correlation with lung function. Am J Respir Crit Care Med 2000; 162: 1102-1108.

32 Nakano Y, Whittall KP, Kalloger SE, Coxson HO, Pare PD, English JC. Development and validation of human airway analysis algorithm using multidetector row CT. Proc SPIE 2002; 4683: 460-469.

33 Coxson HO, Mayo JR, Behzad H, et al. Measurement of lung expansion with computed tomography and comparison with quantitative histology. J Appl Physiol 1995; 79: $1525-1530$
34 Coxson $\mathrm{HO}$, Rogers RM, Whittall KP, et al. A quantification of the lung surface area in emphysema using computed tomography. Am J Respir Crit Care Med 1999; 159: 851-856.

35 de Jong PA, Ottink MD, Robben SG, et al. Pulmonary disease assessment in cystic fibrosis: comparison of CT scoring systems and value of bronchial and arterial dimension measurements. Radiology 2004; 231: 434-439.

36 de Jong PA, Nakano Y, Hop WC, et al. Changes in airway dimensions on computed tomography scans of children with cystic fibrosis. Am J Respir Crit Care Med 2005; 172: 218-224.

37 de Jong PA, Nakano Y, Lequin $\mathrm{MH}$, et al. Estimation of lung growth using computed tomography. Eur Respir J 2003; 22: 235-238.

38 Long FR, Castile RG. Technique and clinical applications of full-inflation and end-exhalation controlled-ventilation chest CT in infants and young children. Pediatr Radiol 2001; 31: 413-422.

39 Long FR. High-resolution CT of the lungs in infants and young children. J Thorac Imaging 2001; 16: 251-258.

40 Long FR, Castile RG, Brody AS, et al. Lungs in infants and young children: improved thin-section CT with a noninvasive controlled-ventilation technique - initial experience. Radiology 1999; 212: 588-593.

41 Hogg JC, Nespzy S. Regional lung volume and pleural pressure gradient estimated from lung density in dogs. J Appl Physiol 1969; 27: 198-203.

42 Coppoletta J, Wolbach S. Body length and organ weights of infants and children. J Path 1933; 9: 55-70.

43 Bar-Yishay E, Shulman DL, Beardsmore CS, Godfrey S. Functional residual capacity in healthy preschool children lying supine. Am Rev Respir Dis 1987; 135: 954-956.

44 Castile R, Filbrun D, Flucke R, Franklin W, McCoy K. Adult-type pulmonary function tests in infants without respiratory disease. Pediatr Pulmonol 2000; 30: 215-227.

45 Zapletal A. Lung function in children and adolescents. In: Herzog H, ed. Progress in respiration research. Basel, Switzerland, Karger, 1987; pp. 173-196.

46 Amirav I, Kramer SS, Grunstein MM, Hoffman EA. Assessment of methacholine-induced airway constriction by ultrafast high-resolution computed tomography. J Appl Physiol 1993; 75: 2239-2250.

47 Griscom NT, Wohl ME. Dimensions of the growing trachea related to body height. Length, anteroposterior and transverse diameters, cross-sectional area, and volume in subjects younger than 20 years of age. Am Rev Respir Dis 1985; 131: 840-844.

48 Griscom NT, Wohl ME, Fenton T. Dimensions of the trachea to age 6 years related to height. Pediatr Pulmonol 1989; 6: 186-190.

49 Effmann EL, Fram EK, Vock P, Kirks DR. Tracheal crosssectional area in children: CT determination. Radiology 1983; 149: 137-140.

50 Nakano Y, Wong JC, de Jong PA, et al. The prediction of small airway dimensions using computed tomography. Am J Respir Crit Care Med 2005; 171: 142-146.

51 Brown RH, Mitzner W. Effect of lung inflation and airway muscle tone on airway diameter in vivo. J Appl Physiol 1996; 80: 1581-1588. 